\title{
Antioxidant, cytotoxic and hypolipidemic activities of Plumeria alba L. and Plumeria rubra L.
}

\author{
Hafizur Rahman ${ }^{1}$, Vijaya Badra Reddy ${ }^{1}$, Soumya Ghosh², Sandeep Kumar Mistry ${ }^{1}$, \\ Geetika Pant ${ }^{1}$, Sibi G. ${ }^{1}$ \\ ${ }^{1}$ Department of Biotechnology, Indian Academy Degree College, Centre for Research and Post Graduate Studies, Bangalore, INDIA \\ ${ }^{2}$ Department of Microbiology, Indian Academy Degree College, Centre for Research and Post Graduate Studies, Bangalore, INDIA
}

\section{Email address:}

way2geetika@gmail.com (Geetika P.)

\section{To cite this article:}

Hafizur Rahman, Vijaya. B., Soumya Ghosh, Sandeep Kumar Mistry, Geetika Pant, Sibi G.. Antioxidant, Cytotoxic and Hypolipidemic Activities of Plumeria alba L. and Plumeria rubra L.. American Journal of Life Sciences. Special Issue: Recent Developments in Health Care through Plants and Microbes. Vol. 2, No. 6-1, 2014, pp. 11-15. doi: 10.11648/j.ajls.s.2014020601.13

\begin{abstract}
Methanolic flower extracts of Plumeria alba and P. rubra were tested for in vitro antioxidant potential, cytotoxicity and hypolipidemic activities. DPPH assay of methanolic extract of Plumeria revealed that $81 \%$ and $72 \%$ inhibition by $P$. alba and P. rubra respectively and the total phenolic content was found as $173.9 \mu \mathrm{g} \mathrm{ml}^{-1}$ and $167.3 \mu \mathrm{g} \mathrm{ml}{ }^{-1}$. Significant free radical scavenging activities of $1.74 \mathrm{mg} \mathrm{ml}^{-1}$ and $1.67 \mathrm{mg} \mathrm{ml}^{-1}$ were observed due to the higher phenolic content. Anti-chlolesterol assay of the extracts demonstrated P. rubra has highest hypolipidemic activity (60\%) followed by $P$. alba (52\%). MTT assay using HCT 116 cell lines revealed the antiproliferative and cytotoxic activities of $P$. alba with an IC50 value of $259.9 \mu \mathrm{g} \mathrm{ml}^{-1}$. Plumeria species could be a new source of drugs for the treatment of colon cancer and hyperlipidemic conditions due to higher antioxidant potential and phenolic content which was revealed from the study.
\end{abstract}

Keywords: Plumeria, Antioxidant, Anticancer, Anti-Cholesterol, Colon Cancer

\section{Introduction}

Medicinal plants are an important source of new chemical entities with potential therapeutic values. More than $75 \%$ of the total population in developing countries relies on traditional medicines based on plant products [1]. Cancer has a high morbidity and mortality worldwide and the treatment comprise radiation therapy, surgery, chemotherapy, immunotherapy and hormonal therapy [2]. Most of the therapies being used for cancer treatment often lead to serious side effects and novel anticancer drugs developed from natural resources may increase the efficacy of conventional cancer treatment methods. Natural products from plants are important sources of new drugs [3]. Unlike synthetic medicines, medicinal plants promote the natural functions of the body [4]. Some of these agents compared to purely synthetic drugs have higher activity and lower toxicity [5]. Many plants have been identified as having potential antioxidant activities The antioxidant capacities of plant extracts are due to their radical scavenging activity, binding of transition metal ion catalysts, increasing endogenous status of antioxidant enzymes to prevent oxidative damage [6]. Hyperlipidemia is considered as a risk factor involved in the development of cardiovascular disease [7]. Pharmacologists and chemists have been perplexing by the characteristic profiles of toxic side effects of hypolipidemic drugs. There are reports of herbal medicines exerting good hypolipidemic actions [8-10].

Plumeria commonly known as Frangipani belongs to the family Apocyanaceae. Plumeria alba grows as 4-5 $\mathrm{m}$ high tree and leaves are lanceolate. The flower of the plant is white with yellow center [11]. Plumeria rubra grows as a spreading shrub or small tree to a height of $2-8 \mathrm{~m}$ and similar width. The large green leaves can reach $30-50 \mathrm{~cm}$ long and are arranged alternately and clustered at the end of the branches. The flowers are terminal, appearing at the ends of branches, often profuse and very prominent, strongly fragrant and have five petals. The colours range from common pink to white with shades of yellow in the centre of the flower [12]. Plumeria species have been reported to have antimicrobial $[13,14]$, anticancer [15-18], antipyretic [19] and antioxidant [20] activities. The present attempt is to determine the antioxidant, anti-cancer and hypolipidemic activities of Plumeria alba and P. rubra flower extracts. 


\section{Materials and Methods}

\subsection{Plant Material Collection and Extraction}

Fresh flowers of Plumeria alba and P. rubra were collected from local areas of Bangalore, air dried, ground into powder and sieved (60 mesh). About $100 \mathrm{~g}$ of dried flower powder was extracted in methanol $(1: 7 \mathrm{w} / \mathrm{v})$ at $25^{\circ} \mathrm{C}$ for 24 hours. The extracts were centrifuged at $10,000 \mathrm{rpm}$ for 10 minutes and the supernatant was filtered using Whatman No.1 filter paper and concentrated to dryness under reduced pressure in rotary vacuum evaporator. The final extract was stored in air tight containers at $4^{\circ} \mathrm{C}$ until used.

\subsection{DPPH Assay}

The capacity of the extract to scavenge the stable 2, 2'diphenyl-2-picrylhydrazyl (DPPH) free radical was determined according to the method reported by Gyamfi et al., [21]. In brief, $50 \mu \mathrm{l}$ of the methanolic flower extract $\left(100 \mu \mathrm{g} \mathrm{ml}^{-1}\right)$ was mixed with $1.8 \mathrm{ml}$ of $0.5 \mathrm{mM} \mathrm{DPPH}$ in methanol solution. Methanol $(50 \mu \mathrm{l})$ was used as the experimental control. After $30 \mathrm{~min}$ of incubation at room temperature, the reduction in the number of DPPH free radicals was measured at $517 \mathrm{~nm}$. The percent inhibition was calculated from the following equation:

$$
\text { Inhibition }(\%)=\frac{\left(\text { Control }_{\mathrm{A} 517}-\text { Sample }_{\mathrm{A} 517}\right)}{\text { Control }_{\mathrm{A} 517}} \times 100
$$

\subsection{Determination of Total Phenolic Content}

The amount of total phenolics in the flower extract was determined with Folin-Ciocalteu (FC) reagent [22]. To 200 $\mu 1$ of sample (3 replicates), $1 \mathrm{ml}$ of $1: 2$ dilution of FC reagent and $800 \mu \mathrm{l}$ of sodium carbonate $(7.5 \% \mathrm{w} / \mathrm{v})$ were added and the resulting mixture was incubated at room temperature for 30 minutes. The absorbance of the sample was measured at $765 \mathrm{~nm}$ using a spectrophotometer and the results were expressed as milligram of gallic acid equivalent per gram of dry weight.

\subsection{Antioxidant Potential Assay}

The Antioxidant potential assay was carried out by

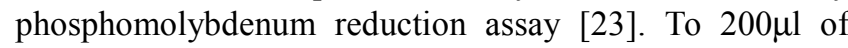
flower extract, $1 \mathrm{ml}$ of the reagent containing $4 \mathrm{mM}$ ammonium molybdate, $28 \mathrm{mM}$ sodium phosphate and 0.6 $\mathrm{M}$ sulphuric acid were added and the resulting mixture was incubated at $37^{\circ} \mathrm{C}$ for 60 minutes. The absorbance of samples were measured at $695 \mathrm{~nm}$ using a spectrophotometer against blank using methanol. The antioxidant potential activity was expressed as $\mathrm{mg}$ of ascorbic acid equivalent per gram of dry weight.

\subsection{In Vitro Anti-Cholesterol Assay}

The anti-cholesterol assay was carried out as described by Iswantini et al., [24] and Cholesterol Enzymatic Endpoint Method [25]. Cholesterol was dissolved in chloroform until achieving $25 \mathrm{mg} / 10 \mathrm{ml}$. $10 \mu \mathrm{l}$ of the flower extract (two concentrations) were pipetted into micro titre plate followed by the addition of $2000 \mu \mathrm{l}$ of Randox reagent and $10 \mu \mathrm{l}$ of cholesterol as sample. $20 \mu \mathrm{l}$ of distilled water and $2000 \mu \mathrm{l}$ of Randox reagent were used as blank. Negative control comprised of $20 \mu \mathrm{L}$ cholesterol and $2000 \mu \mathrm{l}$ Randox reagent; standard comprised of $20 \mu \mathrm{l}$ simvastatin and $2000 \mu \mathrm{l}$ Randox reagent. The contents were mixed and incubated for 10 minutes at room temperature. The absorbance was read at $500 \mathrm{~nm}$ in a microplate reader against reagent blank.

\subsection{MTT Assay}

The flower extracts were tested for in vitro cytotoxicity using HCT-116 cells by 3-(4,5-dimethylthiazol-2-yl)-2,5diphenyltetrazolium bromide (MTT) assay [26]. HCT 116 (70-80\%) confluent cell lines were trypsinized followed by viability checking and centrifugation. In a 96 well plate, $5 \mathrm{x}$ $10^{4}$ cells/ well were seeded and incubated for $24 \mathrm{hrs}$ at $37^{\circ} \mathrm{C}$ in a humidified $5 \% \mathrm{CO}_{2}$ incubator. Plant extracts of varying concentrations ranging from $0-320 \mu \mathrm{g} / \mathrm{ml}$ (two fold variations) in RPMI media without fetal bovine serum (FBS) and antibiotics were incubated for $24 \mathrm{hrs}$. After incubation with flower extracts, the media was removed from the wells and added $100 \mu \mathrm{l} /$ well $(50 \mu \mathrm{g} /$ well $)$ of the MTT $(5 \mathrm{mg} / 10 \mathrm{ml}$ of MTT in 1x PBS, the solution was filtered through a $0.2 \mu \mathrm{m}$ filter and stored at $2-8{ }^{\circ} \mathrm{C}$ for frequent use or frozen for extended periods) working solution was added and incubated for 3 to 4 hours. After incubation with MTT reagent, the media was removed from the wells and added $100 \mu \mathrm{l}$ of DMSO to rapidly solubilize the formazan. The absorbance for each well was measured at $590 \mathrm{~nm}$ in a microtitre plate reader and the percentage inhibition was calculated using the formula.

$$
\text { Inhibition }(\%)=\frac{\left(\text { Control }_{\mathrm{A} 590}-\text { Sample }_{\mathrm{A} 590}\right)}{\text { Control }_{\mathrm{A} 590}} \times 100
$$

\section{Results}

Methanolic flower extracts of Plumeria alba and $P$. rubra were used for biological assays. DPPH assay of methanolic extract of Plumeria revealed that $81 \%$ and $72 \%$ inhibition by $P$. alba and $P$. rubra respectively thereby confirming the presence of antioxidants (Fig-1). The total phenolic content of $P$. alba and P. rubra was determined spectrophotometrically by the Folin-Ciocalteu method using gallic acid as internal standard (Fig-2) and it was found as $173.9 \mu \mathrm{g} \mathrm{ml}^{-1}$ and $167.3 \mu \mathrm{g} \mathrm{ml}^{-1}$ (Fig-3). Total antioxidant potential was carried out using ascorbic acid (Fig-4) and was determined as $1.74 \mathrm{mg} \mathrm{ml}^{-1}$ and $1.67 \mathrm{mg}$ $\mathrm{ml}^{-1}$ (Fig-5). In vitro anti-cholesterol activity of Plumeria flowers were examined using simvastatin as the standard drug for a total half an hour at 10 minutes intervals. The purple colour developed during the reaction was decreased with increasing time and $52 \%$ activity was observed at the end of the reaction for $P$. alba whereas $60 \%$ activity was found with $P$. rubra (Fig-6). The standard drug, simvastatin 
has exhibited $94 \%$ anticholesterol activity under in vitro conditions. Cytotoxic assay using colon cancer cell lines (HCT 116) revealed the antiproliferative activity of Plumeria against HCT 116 cell lines. Plumeria alba has exhibited dose dependent cytotoxicity whereas $P$. rubra was completely failed to control the proliferation of colon cancer cells. Loss of viability of the dying cells as evidenced by the morphological changes was scrutinized by microscopy. Depending on the concentration, the extract exhibited different levels of cytotoxicity like cell shrinkage, aggregation and cell death with an IC50 value of $259.9 \mu \mathrm{g}$ $\mathrm{ml}^{-1}$ (Fig-7) was observed with P. alba.

\section{Discussion}

Research studies have found that methanol is the best reagent for extraction because it can easily penetrate the cell wall. In addition, many useful compounds have been found in methanol extracts [27]. In this study, 98\% methanol was used in the extraction of Plumeria flowers. Natural antioxidants are generally more desirable for consumption than the synthetic one such as butylated hydroxyanisole (BHA) which was reported to be carcinogenic to humans [28]. The antioxidant activity is mainly due to their redox properties, which can play an important role in chelating transitional metals and scavenging free radicals [29]. For evaluation of free radical scavenging properties of $P$. alba and P. rubra, DPPH assay was performed using ascorbic acid as standard compound. Higher scavenging activity of free radicals was observed in both $P$. alba and P. rubra flower extracts which could be attributed by the presence of high phenolic content.

Cancer is a class of diseases characterized by unregulated cell growth. The World Health Organization has reported that approximately $13 \%$ of all deaths in the world are caused by cancer each year. Colorectal cancer is one of the most commonly diagnosed cancers worldwide. Death from colon cancer has risen to be the fourth highest among all cancer-related deaths. In our study, the human colon cancer cell (HTT-116) line was used as the target. Approximately $60 \%$ of drugs approved for cancer treatment are of natural origin [30, 31]. Plants are important sources for the development of potential anticancer agents which many of them have been purified and used as drugs for cancer prevention or treatment [32]. The results of MTT assay revealed that the Plumeria extract exert significant cytotoxicity and antiproliferative action on HCT 116. Oxidative stress is suggested as a mechanism underlying hyperlipidemia, which is one of the major risk factors for coronary artery diseases [33]. In our study, Plumeria species with high phenols showed a good antioxidant activity, which encouraged us to check the hypolipidemic activity in vitro. Both species of Plumeria were exhibited hypolipidemic activity with highest percentage observed in P. rubra $(60 \%)$.

\section{Conclusion}

In conclusion, the results from this study further support the view that Plumeria species are promising source of natural antioxidants. Plumeria alba flowers were found as potential source of antioxidants and cytotoxic activity whereas, $P$. rubra was significant in exhibiting hypolipidemic activity in vitro. The in vivo antioxidant properties of Plumeria flowers should be the objective of future research in new formulation for pharmacological applications.

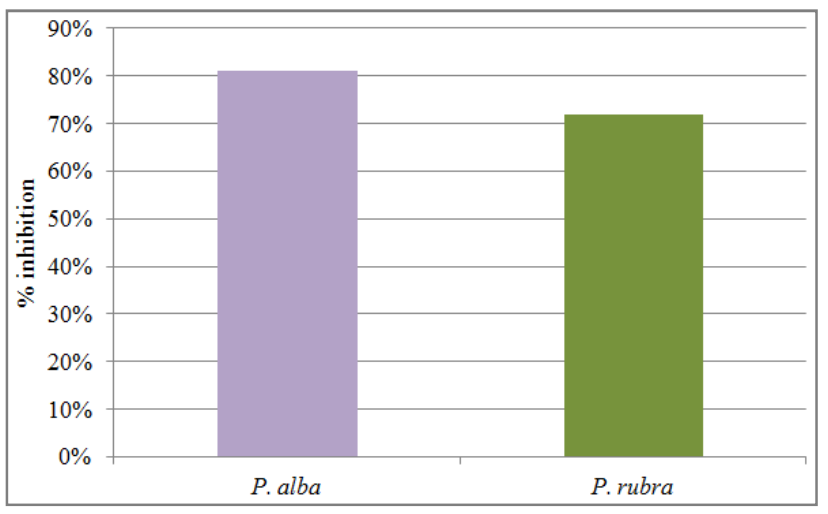

Fig 1. DPPH assay of Plumeria alba and Plumeria rubra

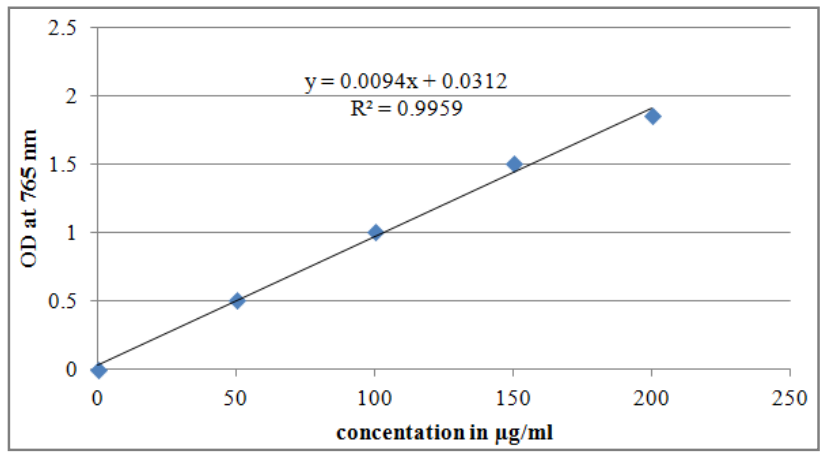

Fig 2. Standard curve for total polyphenols using gallic acid

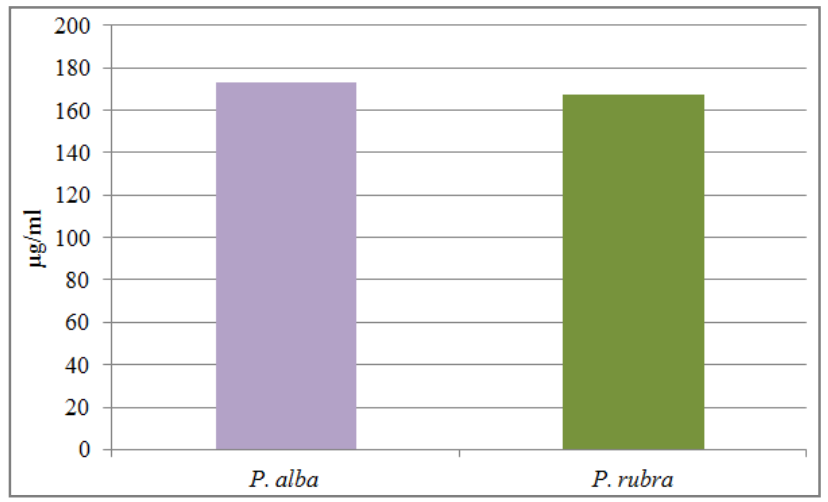

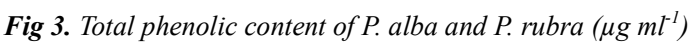




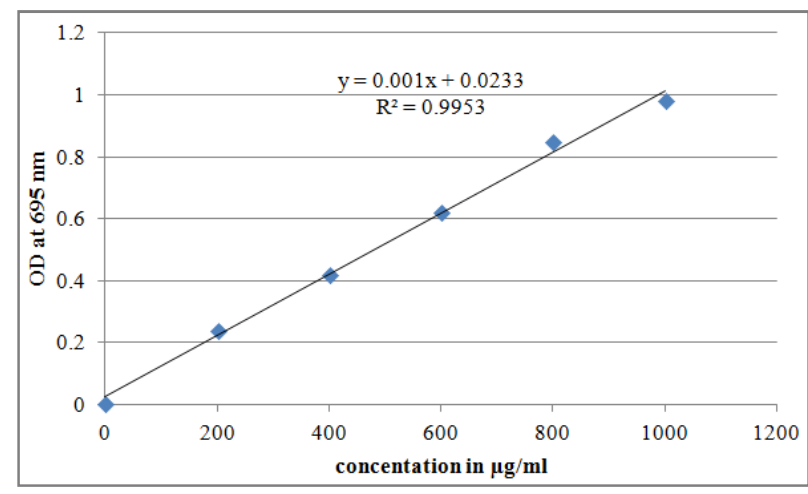

Fig 4. Standard curve for antioxidant potential using ascorbic acid

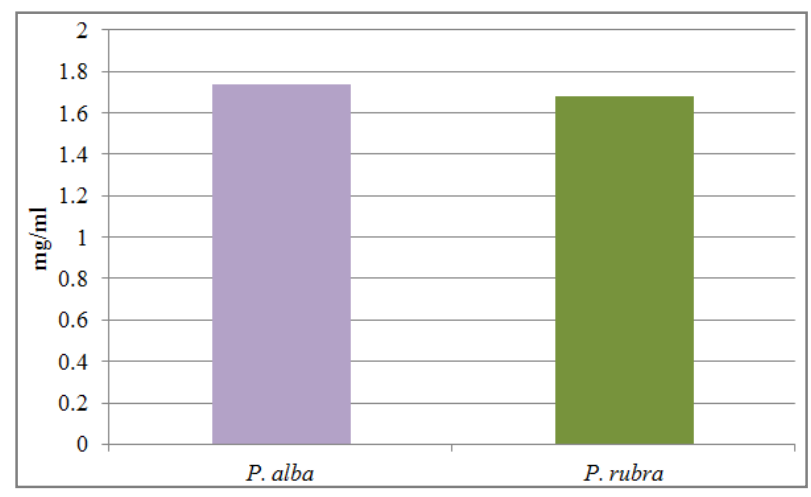

Fig 5. Total antioxidant activity of P. alba and P. rubra ( $\left.m g \mathrm{ml}^{-1}\right)$

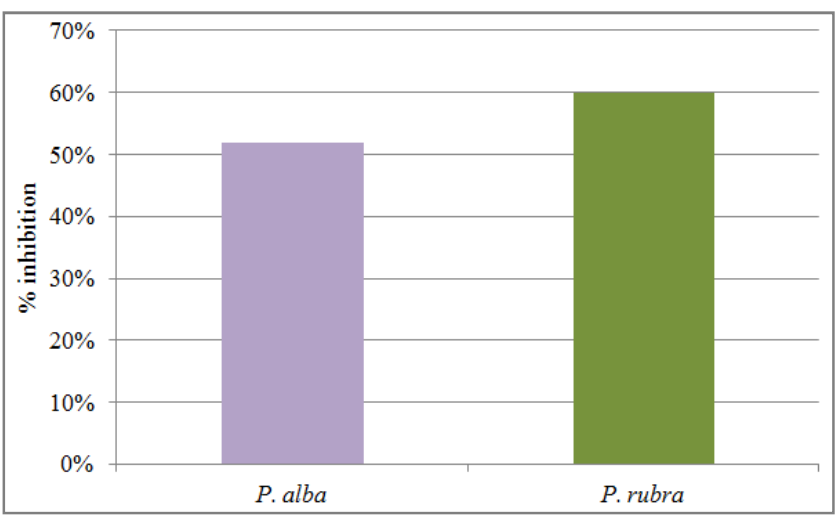

Fig 6. Hypolipidemic activity of P. alba and P. rubra

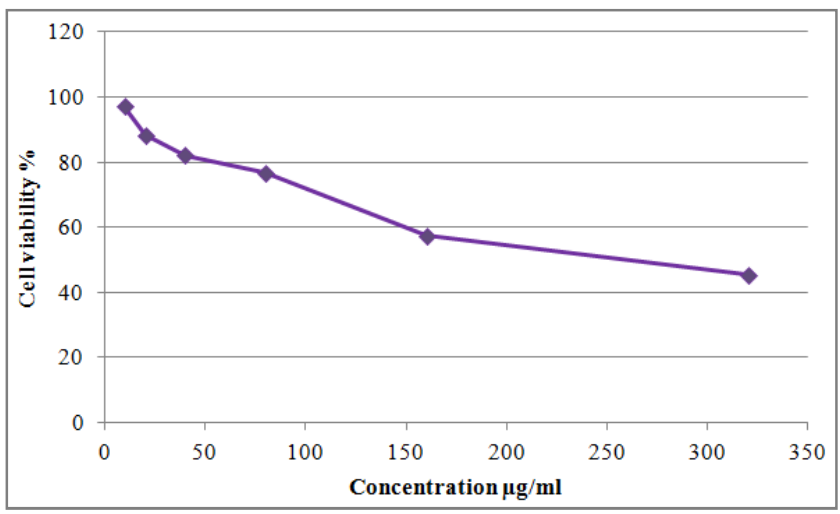

Fig 7. MTT cytotoxic assay of Plumeria alba flowers against HCT 116 cell lines

\section{References}

[1] Organization WH, WHO traditional medicine strategy 20022005 Geneva: World Health Organization; 2002

[2] R. Baskar, K.A. Lee, R. Yeo, K.W. Yeoh, "Cancer and radiation therapy: current advances and future directions," Int J Med Sci., vol. 9, 193-199, 2012.

[3] D.J. Newman DJ, Cragg GM. Natural products as sources of new drugs over the 30 years from 1981 to 2010. J Nat Prod. vol. 75, 311-335, 2012.

[4] C. Li, M.H. Wang, "In vitro biological evaluation of 100 selected methanol extracts from the traditional medicinal plants of Asia," Nutr Res Pract., vol.8, 151-157, 2014.

[5] D.S. Fabricant, N.R. Fransworth, "The value of plants used in traditional medicine for drug discovery," Environ Health Perspect., vol. 109, 69-75, 2001.

[6] W. Zheng, S.Y. Wang, "Antioxidant activity and phenolic compounds in selected herbs," J Agric Food Chem., vol. 49, 5165-5170, 2001.

[7] W.H. Frishman, "Biologic Markers as Predictors of Cardiovascular Disease," Amer. J Med., vol. 104, 18S-27S, 1998.

[8] B.K. Rao, M.M. Kesavulu, R. Giri, C. Apparao, "Antidiabetic and hypolipidemic effects of Momordica cymbalaria Hook. fruit powder in alloxan diabetic rats," $J$ Ethnopharmacol., vol. 67, 103-109, 1999.

[9] B. Sharma, C. Balomajumder, P. Roy, "Hypoglycemic and hypolipidemic effects of flavonoid rich extract from Eugenia jambolana seeds on streptozotocin induced diabetic rats," Food Chem Toxicol., vol. 46, 2376-2383, 2008.

[10] Y.T. Liu, B.N. Lu, L.N. Xu, L.H. Yin, X.N. Wang, J.Y. Peng, K.X. Liu, "The antioxidant activity and hypolipidemic activity of the total flavonoids from the fruit of Rosa laevigata Michx," Natural Science., vol. 2, 175-183, 2010.

[11] R.K. Goyal, G. Goyal, S. Goyal, S. Mittal, "Pharmacognostical evaluation of bark of Plumeria alba Linn," International Journal of Natural Product Science, vol. 1, 178, 2012

[12] F. Edward, D.G. Gilman, Plumeria rubra Middle aged Frangipani. Fact Sheet ST-491. Watson, 1994.

[13] G. Sibi, Saurabh Awasthi, K. Dhananjaya, H. Mallesha and K.R. Ravikumar, Comparative studies of Plumeria species for their phytochemical and antifungal properties against Citrus sinensis pathogens. International Journal of Agricultural Research, vol. 7, 324-331, 2012.

[14] Rasool SN, Jaheerunnisa S, Chitta SK, Jayaveera KN. Antimicrobial activities of Plumeria acutifolia. J Med Plants Res. vol. 2, 77-80, 2008.

[15] R. Radha, T. Sivakumar, "In vitro and in vivo anti-cancer activity of leaves of Plumeria alba Linn," J. Pharm. Res., vol. 2, 203-207, 2009.

[16] R. Radha, S. Kavimani, V. Ravichandran, "Antitumor activity of methanolic extract of Plumeria alba L. leaves against Dalton lymphoma ascites in mice, "Int. J. Health Res., vol. 1, 79-85, 2009. 
[17] J.B. Rekha, B. Jayakar, "Anticancer activity of ethanolic extract of leaves of Plumeria rubra (Linn.)," Current Pharma Tech, CPR1(2): 175-179, 2011.

[18] M.P. Dobhal, G. Li, A. Gryshuk, A. Graham, A.K. Bhatanager, S.D. Khaja, Y.C. Joshi, M.C. Sharma, A. Oseroff, R.K. Pandey, "Structural modifications of plumieride isolated from Plumeria bicolor and the effect of these modifications on in vitro anticancer activity," J Org Chem., vol. 69, 6165-6172, 2004.

[19] M. Gupta, U.K. Mazumder, P. Gomathi, "Evaluation of antipyretic and antiociceptive activities of Plumeria accuminata leaves," J. Med. Sci, vol. 7, 835-839, 2007.

[20] A.J. Merina, D. Sivanesan, V.H. Begum, N. Sulochana, "Antioxidant and hypolipidemic effect of Plumeria rubra L. in alloxan induced hyperglycemic rats," E-Journal of Chemistry, vol. 7,1-5, 2010.

[21] M.A. Gyamfi, M. Yonamine, Y. Aniya, "Free radical scavenging action of medicinal herbs from Ghana: Thonningia sanguinea on experimentally induced liver injuries," Gen Pharmacol, vol. 32, 661-667, 1999.

[22] E.A. Ainsworth, K.M. Gillespie, Estimation of total phenolic content and other oxidation substrates in plant tissues using Folin-Ciocalteu reagent. Nature Protocols, vol. 2, 875-877, 2007.

[23] P. Prieto, M. Pineda, M. Aguilar M, "Spectrophotometric quantitation of antioxidant capacity through the formation of a Phosphomolybdenum Complex: Specific application to the determination of vitamin E," Anal Biochem, vol. 269, 337 $341,1999$.

[24] D. Iswantini, D. Nurenda dan, P. Sugita, "Fractionation and characterization of active compounds from Bangle (Zingiber Cassumunar Roxb.) as an activator of the enzyme cholesterol oxidase," Simposium Nasional Kimia Bahan Alam XV. Himpunan Kimia Bahan Alam. Bogor., 2005
[25] Randox Laboratories, "Cholesterol (Chol) enzymatic endpoint method manual," 2009.

[26] S.P.M. Crouch, R. Kozlowski, K.J. Slater, J. Fletcher, "The use of ATP bioluminescence as a measure of cell proliferation and cytotoxicity". J. Immunol. Methods., vol. $160,81-88,1993$.

[27] M. Henriques, A. Silva, J. Rocha. "Extraction and quantification of pigments from a marine microalga: a simple and reproducible method". In: Mendez-Vilas A, editor. Communicating Current Research and Educational Topics and Trends in Applied Microbiology. Madrid: Formatex; pp. 586-593, 2007.

[28] V. Ani, K.A. Naidu, "Antioxidant potential of bitter cumin (Centratherum anthelminticum (L.) Kuntze) seeds in in vitro models," BMC Complement Altern., vol. 13: 40, 2011.

[29] A.A. Mohamed, A.A. Khalil, H.E.S. El-Beltagi, "Antioxidant and antimicrobial properties of kaff maryam (Anastatica hierochuntica) and doum palm (Hyphaene thebaica)" Grasas Y Aceites. vol. 61, 67-75, 2010.

[30] M.J. Balunas, A.D. Kinghorn, "Drug discovery from medicinal plants," Life Sci., vol. 78, 431-441, 2005.

[31] M. Gordaliza, "Natural products as leads to anticancer drugs," Clin Transl Oncol vol. 9, 767-776, 2007.

[32] A.G. Desai, G.N. Qazi, R.K. Ganju, M. El-Tamer, J. Singh, A.K. Saxena, Y.S. Bedi, S.C. Taneja, H.K. Bhat, "Medicinal plants and cancer chemoprevention. Curr Drug Metab," vol. 9, 581-591, 2008.

[33] J.C. Fruchart, P. Duriez, "High density lipoproteins and coronary heart disease future prospects in gene therapy," Biochimie, vol. 80, 167-172, 1998. 